\title{
Heat shock protein 70 attenuates hypoxia-induced apoptosis of pulmonary microvascular endothelial cells isolated from neonatal rats
}

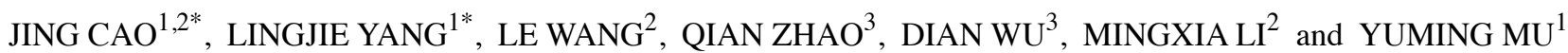 \\ Departments of ${ }^{1}$ Echocardiography and ${ }^{2}$ Neonatology, The First Affiliated Hospital of Xinjiang Medical University; \\ ${ }^{3}$ School of Pediatrics, Xinjiang Medical University, Ürümqi, Xinjiang Uyghur Autonomous Region 830054, P.R. China
}

Received December 10, 2020; Accepted June 15, 2021

DOI: $10.3892 / \mathrm{mmr} .2021 .12327$

\begin{abstract}
Pulmonary microvascular endothelial cell (PMVEC) apoptosis is the initial stage of adult pulmonary hypertension $(\mathrm{PH})$, which involves high pulmonary arterial pressure and pulmonary vascular remodeling. However, the mechanism regulating PMVEC apoptosis and its involvement in the early stages of neonatal hypoxic PH (HPH) pathogenesis are currently unclear. The present study aimed to investigate the effects of heat shock protein 70 (HSP70) on hypoxia-induced apoptosis in PMVECs. PMVECs isolated from neonatal Sprague-Dawley rats were transfected with lentivirus with or without HSP70, or treated with the synthetic HSP70 inhibitor N-formyl-3,4-methylenedioxy-benzylideneg-butyrolactam under hypoxic conditions $\left(5 \% \mathrm{O}_{2}\right)$ for 24,48 or $72 \mathrm{~h}$. PMVEC apoptosis was evaluated by performing flow cytometry and mitochondrial membrane potential (MMP) assays. The expression levels of HSP70, hypoxia-inducible factor-1 $\alpha$ (HIF-1 $\alpha)$ and apoptosis-associated proteins were determined by conducting reverse transcription-quantitative
\end{abstract}

Correspondence to: Dr Yuming Mu, Department of Echocardiography, The First Affiliated Hospital of Xinjiang Medical University, 137 Liyushan Road, Ürümqi, Xinjiang Uyghur Autonomous Region 830054, P.R. China

E-mail: mym1234@126.com

Dr Mingxia Li, Department of Neonatology, The First Affiliated Hospital of Xinjiang Medical University, 137 Liyushan Road, Ürümqi, Xinjiang Uyghur Autonomous Region 830054, P.R. China E-mail:1mx12032020@163.com

*Contributed equally

Abbreviations: PMVEC, pulmonary microvascular endothelial cell; $\mathrm{PH}$, pulmonary hypertension; HPH, hypoxic pulmonary hypertension; MMP, mitochondrial membrane potential; HSP, heat shock protein; AIF, apoptosis-inducing factor; HIF-1, hypoxia-inducible factor-1; cyt $\mathrm{C}$, cytochrome $c$

Key words: HSP70, HIF-1 $\alpha$, apoptosis, endothelial cells, neonatal hypoxic pulmonary hypertension
PCR and western blotting. Following 24,48 or $72 \mathrm{~h}$ of hypoxia, the apoptotic rates of PMVECs were significantly elevated compared with cells under normoxic conditions. The MMP was significantly reduced, whereas the mRNA and protein expression levels of HIF-1 $\alpha$, cytochrome $c$ (cyt C), caspase-3 and HSP70 were enhanced by hypoxia compared with those under normoxic conditions. Additionally, the mRNA and protein expression levels of B-cell lymphoma 2 (Bcl-2) were significantly downregulated in the hypoxia group compared with those in the normoxia group. In hypoxic PMVECs, HSP70 overexpression decreased the apoptotic rate and the expression levels of cyt $\mathrm{C}$, downregulated the expression levels of caspase-3 and HIF- $1 \alpha$, and increased the MMP and the expression levels of Bcl-2. HSP70 inhibition resulted in the opposite outcomes compared with those of HSP70 overexpression. Therefore, the results of the present study suggested that HSP70 may inhibit mitochondrial pathway-mediated apoptosis in isolated neonatal rat PMVECs in early-stage hypoxia, which may be associated with HSP70-mediated HIF-1 $\alpha$ downregulation. Overall, HSP70 may be protective against neonatal $\mathrm{HPH}$ through the HSP70/HIF-1 $\alpha$ pathway.

\section{Introduction}

Neonatal pulmonary hypertension (PH) is a severe type of $\mathrm{PH}$ in children with an incidence rate of $0.43-6.82$ per 1,000 live births and a mortality rate of $4-33 \%$ according to a study from the National Institute of Child Health and Human Development Neonatal Research Network (1). The etiology of neonatal PH includes hypoxia, parenchymal lung diseases, abnormal pulmonary vascular development, among which hypoxia is the primary cause $(2,3)$. In the early stages of $\mathrm{PH}$, which is characterized by pulmonary vasoconstriction (2), symptomatic treatments, such as vasodilation, are effective to a limited extent (2). However, once the disease progresses towards pulmonary vascular remodeling and right ventricular hypertrophy, the effectiveness of treatments is reduced, leading to a high mortality rate $(4,5)$. Therefore, developing effective strategies for preventing $\mathrm{PH}$ disease progression is essential.

Pulmonary microvascular endothelial cells (PMVECs) serve a central role in the pathogenesis of adult $\mathrm{PH}$ through apoptosis, proliferation and their interactions with other 
pulmonary vascular cell types (6). Sakao et al (7) demonstrated that PMVECs are the early damage sites of $\mathrm{PH}$, and early apoptosis of PMVECs initiates PH pathogenesis. In the early stages of PH, the apoptosis of PMVECs results in a decrease in cellular function, leading to the inactivation of the endothelial nitric oxide lyase, decreased release of the vasodilator nitric oxide and inhibition of PMVEC-mediated pulmonary vascular tension, resulting in pulmonary artery constriction, high pulmonary vascular resistance and high pulmonary artery pressure (8-10). As the disease progresses, cell proliferation predominates over PMVEC apoptosis, resulting in tissue imbalance, which coincides with the formation of plexiform vascular lesions and vascular remodeling $(4,11,12)$. Schultz et al (13) developed a persistant PH mouse model displaying the newborn phenotype by downregulating the superoxide dismutase 2 gene. These mice exhibited high right ventricular systolic pressure, pulmonary artery endothelial cell apoptosis and pulmonary artery smooth muscle cell proliferation, indicating that PMVEC apoptosis may be involved in the pathogenesis of neonatal PH. However, whether PMVECs exhibit an apoptotic phenotype in early hypoxia has not been previously reported, and the regulatory mechanism underlying PMVEC apoptosis remains unclear.

Heat shock proteins (HSPs) are a conserved family of molecular chaperones that protect cells from damage and maintain cellular homeostasis (14). HSP70, which is the most widely studied member of the HSP family, is expressed at low levels in healthy cells under normal environmental conditions. However, under the effects of heat shock, ischemia, hypoxia, nutrient deficiency, irradiation or infection, the expression levels of HSP70 increase compared with those under normal conditions $(14,15)$. HSP70 is also an antiapoptotic protein; high expression levels of HSP70 inhibit apoptosis and promote cell survival, whereas low levels increase the apoptotic rate $(16,17)$. Through its antiapoptotic activity, HSP70 participates in the pathogenesis of various diseases, including heart disease, lung injury and neurodegeneration (18). Researchers have demonstrated that HSP70 is highly expressed in breast cancer and gastric cancer cells, and inhibits apoptosis by acting on multiple sites upstream and downstream of the mitochondrial apoptotic signaling pathway, which may contribute to tumor progression by affecting chemotherapy resistance $(17,19,20)$. During myocardial ischemia, HSP70 expression is increased, which protects cardiac cells by removing or refolding misfolded proteins and inhibiting the activity of apoptosis-inducing factor (AIF) (21). In addition, HSP70 upregulation stimulated by geranylgeranylacetone, a HSP inducer, relieves pneumolysin-induced acute lung injury by reducing human PMVEC apoptosis (22). Kondrikov et al (14) reported that hyperoxia elevates the expression levels of HSP70 in PMVECs, preventing lung endothelial barrier damage by inhibiting caspase-dependent and AIF-dependent apoptosis. However, the role of HSP70 in PMVEC apoptosis in the context of neonatal hypoxic $\mathrm{PH}(\mathrm{HPH})$ remains unclear.

Hypoxia-inducible factor-1 (HIF-1), a key regulator of hypoxia, is a heterodimer composed of HIF- $1 \alpha$ and HIF-1 $\beta$ (23). The expression levels of HIF-1 $\alpha$ are increased under hypoxia and determine the transcriptional activation of HIF-1 (24). HIF-1 $\alpha$ participates in a variety of hypoxia-related diseases by promoting transcriptional activation of its downstream target genes (25). In our previous study, induction of HIF-1 $\alpha$ and its downstream factors, nitric oxide synthase and endothelin-1, promoted HPH progression in neonatal rats (26). In addition, recent studies have demonstrated that HIF- $1 \alpha$ serves an important role in vascular endothelial cell apoptosis $(27,28)$. Therefore, it has been hypothesized that HIF- $1 \alpha$ may be involved in HSP70-mediated regulation of PMVEC apoptosis.

The present study aimed to assess the apoptotic phenotypic changes in PMVECs during the early stages of hypoxia, and elucidate the effects and mechanisms of HSP70 on hypoxia-induced PMVEC apoptosis in neonatal rats.

\section{Materials and methods}

Animals. A total of 87 Sprague-Dawley rats (30 female and 57 male; age, 5-7 days; weight, 10-15 g) were purchased from the Department of Laboratory Animal Science of Xinjiang Medical University. All neonatal rats were given adaptive feeding after birth and were maintained in a $12 \mathrm{~h}$ light/dark cycle at $22-25^{\circ} \mathrm{C}$ and $55-60 \%$ humidity. Animal health and behavior were monitored once a day. Every effort was made to minimize animal numbers and suffering. The specific criteria used to determine when to euthanize an animal included lethargy, lack of appetite, lost organ function and rapid weight loss ( $>10 \%$ body weight). No rats were euthanized or found dead during the course of the present study. Neonatal rats were anesthetized with an intraperitoneal injection of $100 \mathrm{mg} / \mathrm{kg}$ ketamine and $10 \mathrm{mg} / \mathrm{kg}$ xylazine followed by sacrifice via cervical dislocation. In the present study, the criteria for verifying animal death were as follows: No spontaneous respiration, no heartbeat, no corneal reflex and gray skin. All animal experiments were approved by the Animal Ethics Committee of The First Affiliated Hospital of Xinjiang Medical University (approval no. IACUC-20170214029; Urumqi, China).

Cell isolation, culture and identification. PMVECs were extracted from lung tissue samples of newborn rats by the tissue adhesion method (29). Lungs were extracted from neonatal rats and placed in DMEM (Thermo Fisher Scientific, Inc.). The pleura and lung tissue edges $(2 \mathrm{~mm})$ were removed and then $1 \mathrm{~mm}^{3}$ sections were excised from the marginal lung tissue and incubated at $37^{\circ} \mathrm{C}$ for $30 \mathrm{~min}$. The tissue blocks were uniformly placed in a 6-well plate (30 pieces/well) and coated with poly-D-lysine (Sigma-Aldrich; Merck KGaA). Following tissue block solidification and attachment to the culture plate at $37^{\circ} \mathrm{C}$ with $5 \% \mathrm{CO}_{2}$ for $90 \mathrm{~min}, 750 \mu 1$ PMVEC primary culture medium containing DMEM (Gibco; Thermo Fisher Scientific, Inc.), 20\% FBS (Gibco; Thermo Fisher Scientific, Inc.) and $1 \%$ penicillin-streptomycin (Beyotime Institute of Biotechnology) was added to each well. Cell morphology was examined using an optical microscope (Nikon Instruments Inc.). PMVECs were digested with $0.25 \%$ trypsin (Beyotime Institute of Biotechnology) at $37^{\circ} \mathrm{C}$ for $5 \mathrm{~min}$ and $3-5 \times 10^{5}$ cells were collected after centrifugation at $1,000 \mathrm{x}$ g for $5 \mathrm{~min}$. In the present study, three batches of cell culture were used. Primary cells were cultured on glass cover slips and fixed with 4\% paraformaldehyde (Sangon Biotech Co., Ltd.) at room temperature for $15 \mathrm{~min}$. Subsequently, the cell samples were blocked with $6 \%$ normal goat serum (HyClone; Cytiva) at room 
temperature for $30 \mathrm{~min}$. Following incubation with a rabbit monoclonal antibody targeting CD31 (1:100; cat. no. ab222783; Abcam) overnight at $4^{\circ} \mathrm{C}$ (the control cells were incubated with PBS instead of the CD31 antibody), the samples were washed and incubated with an Alexa Fluor 488-conjugated goat anti-rabbit secondary antibody (1:800; cat. no. ab150077; Abcam) at $37^{\circ} \mathrm{C}$ for $30 \mathrm{~min}$. The samples were rinsed three times with $1 \mathrm{X}$ PBS and incubated with DAPI (Beyotime Institute of Biotechnology) for $5 \mathrm{~min}$ in the dark at room temperature. Antifade Mounting Medium (Beyotime Institute of Biotechnology) was subsequently added, and images were acquired using a TCS SP8 confocal laser scanning microscope (Leica Microsystems, Inc.).

Overexpression and inhibition of HSP70. PMVECs were assigned into four groups: i) Hypoxia (HX), PMVECs transduced with an empty lentivirus (LV-Null) and cultured under hypoxic conditions; ii) normoxia (NX), PMVECs transduced with LV-Null and cultured under normoxic conditions; iii) HX + HSP70, PMVECs transduced with a lentivirus with HSP70-overexpression lentivirus (LV-HSP70) and cultured under hypoxic conditions; and iv) $\mathrm{HX}+\mathrm{HSP} 70+\mathrm{N}$-formyl3,4-methylenedioxy-benzylidene-g-butyrolactam (KNK437; Sigma-Aldrich; Merck KGaA), PMVECs transduced with LV-HSP70 and treated with KNK437 prior to exposure to hypoxia.

LV-HSP70 and LV-Null were provided by Western Biotechnology, Inc. The HSP70 coding sequence was amplified using whole genome synthesis of DNA (NCBI Gene ID: 266759, derived from rat tissues; chemically synthesized by Genscript, Inc.) as a template with Premix Taq $^{\mathrm{TM}}\left(\mathrm{LA} \mathrm{Taq}^{\mathrm{TM}}\right.$ Version 2.0; Takara Biotechnology, Co., Ltd.) and verified via sequencing on the Ion Proton ${ }^{\mathrm{TM}}$ Sequencer (Invitrogen; Thermo Fisher Scientific, Inc.). The forward (F) and reverse (R) primer sequences used for the amplification of HSP70 were 5'-ACT AGTGCCACCATGTCGGTGGATGGG-3' and 5,-GCTCTA GATCAATCAATGTCCATCTC-3', respectively. The thermocycling conditions were as follows: Initial denaturation at $98^{\circ} \mathrm{C}$ for $3 \mathrm{~min} ; 30$ cycles of denaturation cycles at $98^{\circ} \mathrm{C}$ for $10 \mathrm{sec}$ and annealing and elongation at $55^{\circ} \mathrm{C}$ for $30 \mathrm{sec}$ and $72^{\circ} \mathrm{C}$ for 2 min respectively; followed by a final extension step at $72^{\circ} \mathrm{C}$ for $10 \mathrm{~min}$. The HSP70 coding sequence was inserted into the pLVX-IRES-Puro vector (Guangzhou FitGene Biotechnology Co., Ltd.), and namely pLVX-HSP70-IRES-Puro. Using $56.7 \mu \mathrm{l} \mathrm{NDE}^{\mathrm{TM}} 3000$ (Western Technology, Inc.), the empty pLVX-IRES-Puro or pLVX-HSP70-IRES-Puro $(8.04 \mu \mathrm{g})$ vectors were transduced into the $293 \mathrm{~T}$ viral packaging cell line (2-3x106; The Cell Bank of Type Culture Collection of The Chinese Academy of Sciences) together with $8.34 \mu \mathrm{g}$ psPAX2 (Genscript, Inc.) and 2.52 $\mu \mathrm{g}$ pMD2.G plasmids (Genscript, Inc.). The 3rd generation vector system was used. Following incubation at $37^{\circ} \mathrm{C}$, lentivirus particle-rich supernatants were collected at 72 and $96 \mathrm{~h}$ post-transduction. The lentivirus was concentrated at $5,000 \mathrm{x} \mathrm{g}$ for $15 \mathrm{~min}$ at $4^{\circ} \mathrm{C}$ via ultrafiltration using Amicon Ultra-15 (cat. no. UFC910024; EMD Millipore).

Primary PMVECs cultured to the third generation were seeded in 24-well culture plates $\left(3-5 \times 10^{4}\right.$ cells/well). At $\sim 70 \%$ confluency, cells were infected with LV-HSP70 or LV-Null at a multiplicity of infection of 100 and incubated at $37^{\circ} \mathrm{C}$ with $5 \% \mathrm{CO}_{2}$ for $72 \mathrm{~h}$. The infected cells were selected using
$2 \mu \mathrm{g} / \mathrm{ml}$ puromycin. Subsequently, the cells were cultured in hypoxic $\left(5 \% \mathrm{O}_{2}\right)$ or normoxic $\left(21 \% \mathrm{O}_{2}\right)$ environments for 24,48 or $72 \mathrm{~h}$. In order to ensure the consistency and reliability of the present study, these three time points were selected to clarify the apoptotic trend of PMVECs in early hypoxia with reference to relevant previous studies conducted in adults $(30,31)$. KNK437, which is a synthetic reagent that specifically inhibits the synthesis of HSP70 at the transcriptional level (32-34), was dissolved in DMSO and added to the cell medium at a final concentration of $100 \mu \mathrm{M}$. Following treatment with KNK437 at room temperature for $3 \mathrm{~h}$, the PMVECs were subjected to hypoxia as aforementioned.

Apoptotic rate analysis. The apoptotic rate was detected using an Annexin V-PE/7-AAD kit (Tianjin Sungene Biotech Co., Ltd.) according to the manufacturer's protocol. Following treatment, PMVECs were washed twice with $1 \mathrm{X}$ PBS and $1-5 \times 10^{5}$ cells were harvested. The cells were incubated with a mixture of $50 \mu \mathrm{l}$ binding buffer and $5 \mu 1$ 7-Aminoactinomycin D at room temperature in the dark for $15 \mathrm{~min}$. Following the addition of a further $450 \mu \mathrm{l}$ binding buffer, cells were incubated with $10 \mu \mathrm{l}$ Annexin V-PE for $15 \mathrm{~min}$ at room temperature in the dark. After washing with $1 \mathrm{X}$ PBS, the apoptotic rate (early + late apoptosis) was detected and analyzed using CytoFLEX flow cytometer and CytExpert software v2.4.0.28 (Beckman Coulter, Inc.) within $1 \mathrm{~h}$.

Mitochondrial membrane potential (MMP) analysis. PMVECs $\left(1-5 \times 10^{5}\right)$ were harvested and changes in the MMP were detected using a JC-1 MMP Assay kit (cat. no. C2006; Beyotime Institute of Biotechnology) according to the manufacturer's instructions and analyzed using CytoFLEX flow cytometer and CytExpert software v2.4.0.28 (Beckman Coulter, Inc.). In healthy mitochondria, JC-1 aggregates in the mitochondrial matrix to form a polymer that emits strong red fluorescence (excitation wavelength, $585 \mathrm{~nm}$; emission wavelength, $590 \mathrm{~nm}$ ) (35). When the MMP is low or absent, JC-1 is only present in the cytoplasm as a monomer and emits green fluorescence (excitation wavelength, $514 \mathrm{~nm}$; emission wavelength, $529 \mathrm{~nm}$ ) (36). The MMP was measured as the ratio of red-to-green fluorescence intensity.

Reverse transcription-quantitative PCR (RT-qPCR). Total RNA was extracted from PMVECs using an RNA extraction kit (Takara Bio, Inc.) according to the manufacturer's instructions, and reverse transcribed with random primers. RT was performed using the RT kit (Takara Bio, Inc.) following the manufacturer's protocol. Subsequently, qPCR was performed in a $10 \mu 1$ reaction system comprising $1 \mu \mathrm{l}$ DNA template, $5 \mu 1$ 2X PowerUp SYBR ${ }^{\circledR}$ Green Master Mix (Applied Biosystems; Thermo Fisher Scientific, Inc.) and $0.5 \mu \mathrm{l}$ each of forward and reverse primers. Furthermore, the thermocycling conditions used were as follows: Initial denaturation, $50^{\circ} \mathrm{C}$ for $2 \mathrm{~min}$ and $95^{\circ} \mathrm{C}$ for $2 \mathrm{~min}$; 40 cycles of denaturation, $95^{\circ} \mathrm{C}$ for $15 \mathrm{sec}$, and annealing and extension, $60^{\circ} \mathrm{C}$ for $1 \mathrm{~min}$. mRNA expression levels of the target genes quantified using the $2^{-\Delta \Delta \mathrm{Cq}}$ method (37) and normalized to GADPH mRNA expression levels. In the present study, the mRNA expression levels of HSP70, HIF-1 $\alpha, \mathrm{Bcl}-2$, cytochrome $c$ (cyt C) and caspase-3, which are involved in the mitochondrial apoptosis 
A

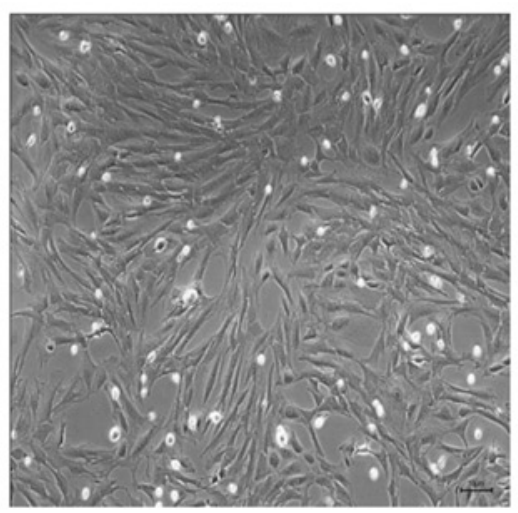

B

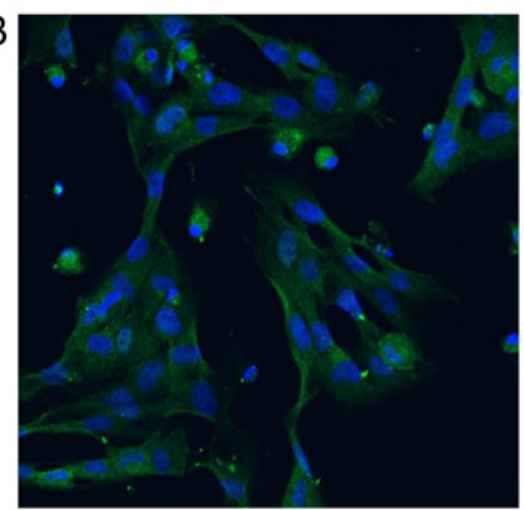

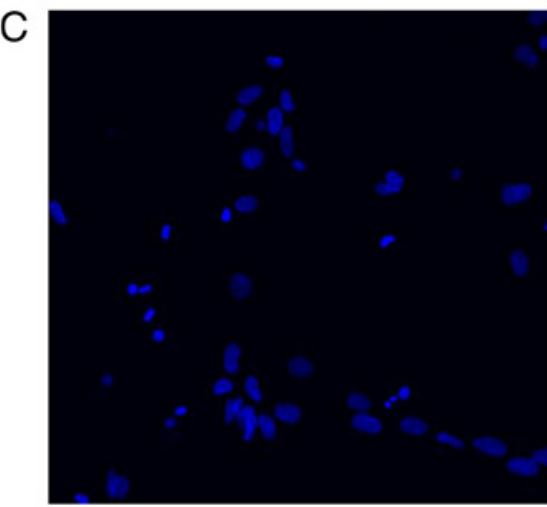

Figure 1. Identification of primary PMVECs isolated from neonatal rats. (A) Under a light microscope (x100 magnification), PMVECs exhibited a polygonal or fusiform morphology and were arranged in a typical cobblestone pattern. (B) Under a confocal laser scanning microscope (x400 magnification), DAPI-stained nuclei (blue) with green fluorescence in the cells representing the expression of CD31, a specific antigen of vascular endothelial cells, confirmed that the cultured cells were PMVECs. (C) Under a confocal laser scanning microscope (x400 magnification), the control cells (PMVECs incubated with PBS instead of the CD31 antibody) exhibited only the blue fluorescence of DAPI in the nuclei. PMVECs, pulmonary microvascular endothelial cells.

pathway $(38,39)$ were examined. The following primers were used: HSP70 F, 5'-CTGTGCTCTGCAGTGTGCAAT-3' and R, 5'-GGCCTCCAGAGTGAACGGT-3'; HIF-1 $\alpha$ F, 5'-ATA CATGGGGTTGACTCAGTTTG-3' and R, 5'-GCTTCGCTG CGTGTTTTGT-3'; Bcl-2 F, 5'-GAGGGGCTACGAGTGGGA TAC-3' and R, 5'-TCAGGCTGGAAGGAGAAGATG-3'; cyt C F, 5'-ACAAAGGCATCATCTGGGGA-3' and R, 5'-TAAGTC TGCCCTTTCTTCCTTCT-3'; caspase-3 F, 5'-CCATAAAAG CACTGGAATGTCAG-3' and R, 5'-CAAAACTGCTCCTTT TGCTGTG-3'; and GAPDH F, 5'-GGCAAGTTCAACGGC ACAG-3' and R, 5'-CGCCAGTAGACTCCACGACAT-3'.

Western blotting. PMVECs were added to radioimmunoprecipitation assay lysis buffer (Beyotime Institute of Biotechnology) to extract total protein, and the amount of protein was determined using the BCA method. The proteins $(20 \mu \mathrm{g})$ were separated via SDS-PAGE on 8,10 or $12 \%$ gels and electroblotted onto PVDF membranes (Bio-Rad Laboratories, Inc.). After blocking with TBS with $0.05 \%$ Tween-20 (TBST) buffer containing $5 \%$ skimmed milk at room temperature for $2 \mathrm{~h}$, the membranes were incubated at $4^{\circ} \mathrm{C}$ overnight with primary rabbit antibodies targeting HSP70 (cat. no. ab181606), HIF-1 $\alpha$ (cat. no. ab216842), Bcl-2 (cat. no. ab196495), caspase-3 (cat.no. ab13847) and GAPDH (cat. no. ab181602), and primary mouse antibodies targeted against cyt C (cat. no. ab13575). All primary antibodies were purchased from Abcam and used at a final dilution of 1:1,000. Following three washes with TBST, the membranes were incubated at room temperature with HRP-labeled secondary antibodies (goat anti-rabbit and goat anti-mouse; cat. nos. A0545-1ML and A4416-1ML; 1:1,000; Sigma-Aldrich; Merck KGaA) for $1.5 \mathrm{~h}$. The membranes were evenly covered with an ECL reagent (Pierce; Thermo Fisher Scientific, Inc.) for $2 \mathrm{~min}$ at room temperature and placed into an exposure instrument for detection. Protein band densities were semi-quantified by the Quantity One software (version 4.6.2; Bio-Rad Laboratories, Inc.), with GAPDH as the loading control.

Statistical analysis. SPSS (version 22.0; IBM Corp.) statistical software was used for all data analyses. Differences among multiple groups were analyzed by one-way or two-way ANOVA followed by Bonferroni's post hoc test. All experiments were conducted with three independent repeats. Data are presented as the mean $\pm \mathrm{SD}$. $\mathrm{P}<0.05$ was considered to indicate a statistically significant difference.

\section{Results}

Identification of PMVECs isolated from neonatal rats. To determine the effects of HSP70 on apoptosis in PMVECs, PMVECs were extracted from the lung tissues of newborn rats. PMVECs exited the lung tissue of normal newborn rats $72 \mathrm{~h}$ following lung tissue attachment to the culture plate. Once fused into a monolayer during culture, PMVECs were analyzed using a light microscope. The results demonstrated that PMVECs displayed a polygonal or fusiform morphology with a typical cobblestone-like arrangement (Fig. 1A). An endothelial cell-specific antibody, anti-CD31, was used to assess the cell via immunofluorescence. The results revealed that the cells expressed CD31, confirming that these cells were PMVECs and could be used to assess the function of HSP70 under hypoxic conditions (Fig. 1B and C).

Hypoxia upregulates the expression levels of HSP70 in PMVECs isolated from neonatal rats. Primary PMVECs from neonatal rats were cultured in a hypoxic environment for 24 , 48 or $72 \mathrm{~h}$. Subsequently, RT-qPCR was performed to evaluate the mRNA expression levels of HSP70 (Fig. 2A). The results revealed that the relative HSP70 mRNA expression levels in the HX group were significantly higher compared with the NX group. Similarly, HSP70 mRNA expression levels were significantly higher in the HX + HSP70 group compared with those in the HX group. By contrast, HSP70 mRNA expression levels in the HX + HSP70 + KNK437 group were significantly lower compared with those in the HX + HSP70 group, suggesting that treatment with KNK437 inhibited HSP70 overexpression at the mRNA level. In addition, western blotting was performed to assess the protein expression levels of HSP70 in PMVECs at 24, 48 and $72 \mathrm{~h}$ time points during exposure to hypoxia (Fig. 2B). The results were consistent with the mRNA 
A

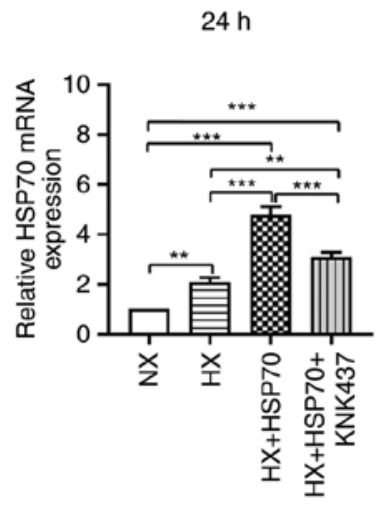

B

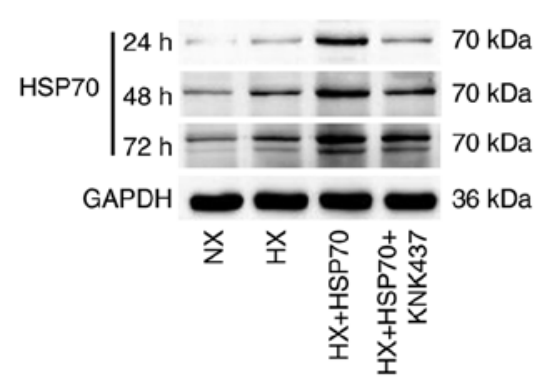

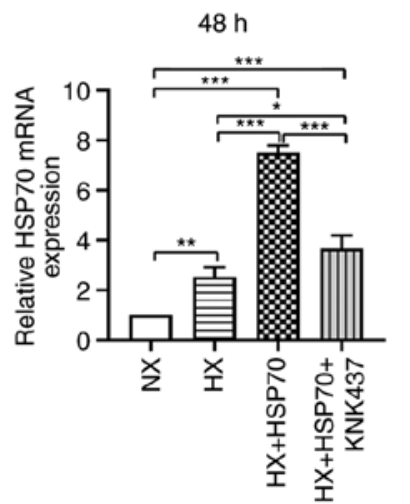

$24 \mathrm{~h}$

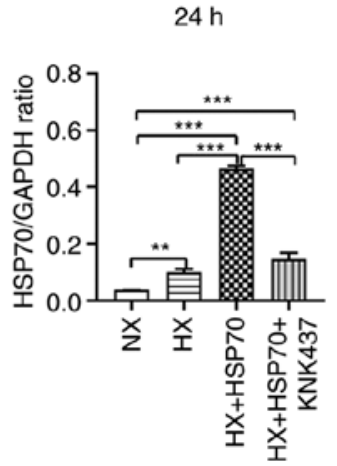

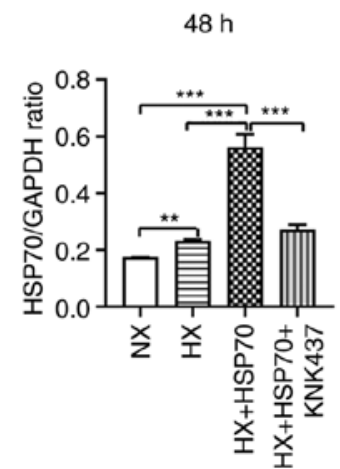

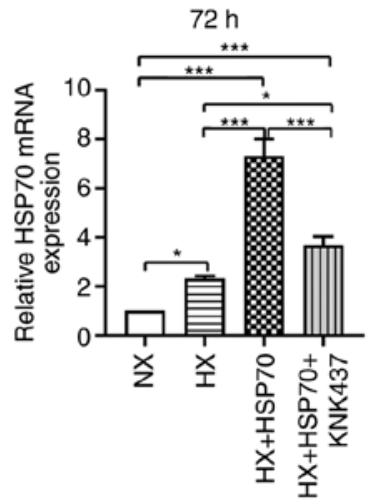

Figure 2. Hypoxia upregulates HSP70 in PMVECs isolated from neonatal rats. Following 24, 48 and 72 h hypoxia exposure, relative HSP70 (A) mRNA and (B) protein expression levels were assessed in the HX, NX, HX + HSP70 and HX + HSP70 + KNK437 groups. GAPDH was used as the loading control. Data are presented as the mean \pm SD from at least three separate experiments, and were analyzed by one-way ANOVA followed by Bonferroni's post hoc test. ${ }^{*} \mathrm{P}<0.05,{ }^{* *} \mathrm{P}<0.01$ and ${ }^{* * *} \mathrm{P}<0.001$. HSP, heat shock protein; PMVECs, pulmonary microvascular endothelial cells; HX, hypoxia; NX, normoxia; KNK437, $\mathrm{N}$-formyl-3,4-methylenedioxy-benzylidene-g-butyrolactam.

expression levels; hypoxia significantly increased the protein expression levels of HSP70 in PMVECs compared with those in the NX group. HSP70 overexpression further increased HSP70 expression in the HX + HSP70 group compared with the HX group. By contrast, KNK437 significantly reduced the protein expression levels of HSP70 compared with those in the HX + HSP70 group. Taken together, these results suggested that hypoxia induced the upregulation of HSP70 mRNA and protein expression levels in the PMVECs of neonatal rats.

HSP70 inhibits hypoxia-induced apoptosis in PMVECs isolated from neonatal rats. In the present study, the effects of HSP70 on the apoptotic rate of hypoxia-treated PMVECs isolated from neonatal rats were evaluated by flow cytometry. The results demonstrated that the apoptotic rate of the HX cell group at 24, 48 and $72 \mathrm{~h}$ was significantly higher compared with the NX group at the same time point, with the increase becoming more notable with longer incubation times (Fig. 3). The apoptotic rate in the HX + HSP70 group was significantly lower compared with that in the HX group, whereas the apoptotic rate was significantly higher in the HX + HSP70 + KNK437 group compared with that in the HX + HSP70 group. These results suggested that HSP70 inhibited apoptosis in PMVECs isolated from neonatal rats under hypoxic conditions.

HSP70 is associated with the mitochondrial apoptotic pathway in PMVECs isolated from neonatal rats. To investigate the association between HSP70 and the mitochondrial apoptotic pathway, changes in the MMP and expression levels of Bcl-2, cyt $\mathrm{C}$ and caspase-3 were examined. The results demonstrated that the MMP was significantly lower in PMVECs exposed to hypoxia for 24,48 and $72 \mathrm{~h}$ compared with that in the corresponding NX group, especially after 72 h (Fig. 4). For all time points, the MMP in the HX + HSP70 group was significantly higher compared with that in the HX group, but significantly lower compared with the NX group. In addition, the MMP was significantly lower in the HX + HSP70 + KNK437 group compared with that in the HX + HSP70 group, and markedly lower compared with the NX group.

RT-qPCR and western blotting were performed to assess the expression levels of the antiapoptotic factor Bcl-2 and the proapoptotic factors cyt $\mathrm{C}$ and caspase-3. The results demonstrated that PMVECs exposed to hypoxia exhibited markedly decreased protein and mRNA expression levels of Bcl-2, and increased protein and mRNA expression levels of cyt $\mathrm{C}$ and caspase- 3 compared with those in the NX group, which was significant for the HX and HX + HSP70 groups (Fig. 5). However, overexpression of HSP70 partly recovered the changes in the mRNA and protein expression levels of Bcl-2, cyt $\mathrm{C}$ and caspase-3 in PMVECs exposed to hypoxia for 24, 48 and $72 \mathrm{~h}$. Furthermore, treatment with KNK437 significantly decreased the expression levels of Bcl-2, and significantly increased the protein and mRNA expression levels of cyt $\mathrm{C}$ and caspase- 3 in PMVECs compared with those in the HX + HSP70 group. The observed effects of HSP70 on the MMP, as well as Bcl-2, cyt C and caspase-3 expression levels suggested that HSP70 exerted its effects on apoptosis via the mitochondrial pathway. 
A

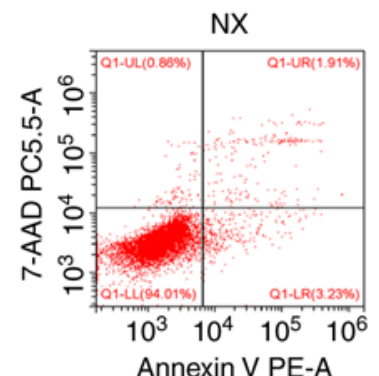

$48 \mathrm{~h}$
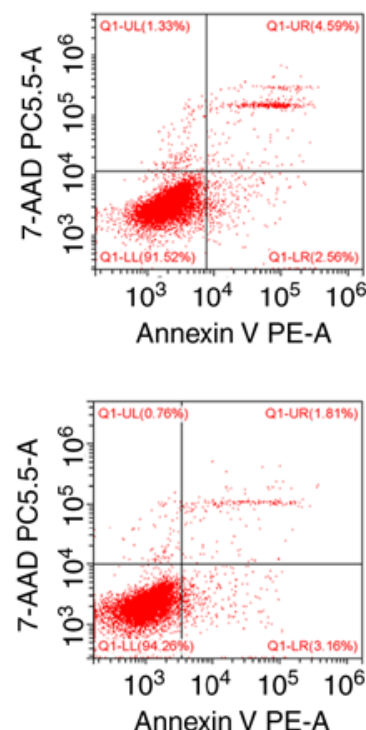
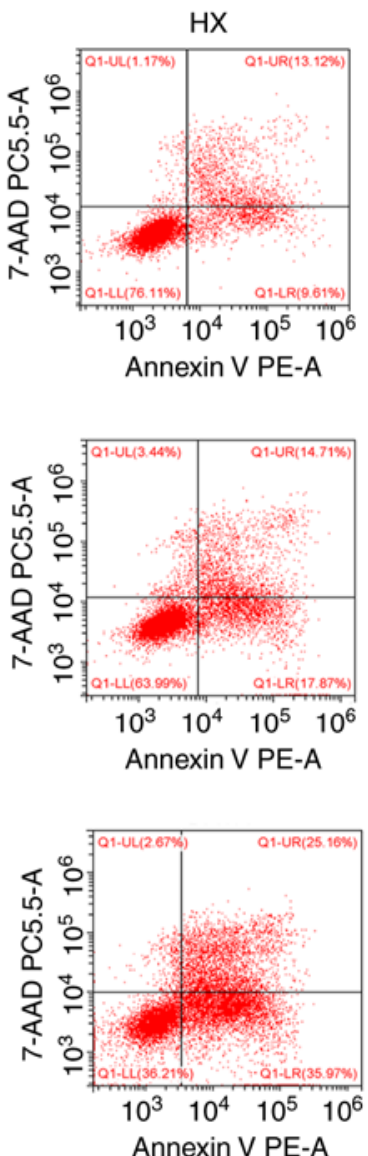
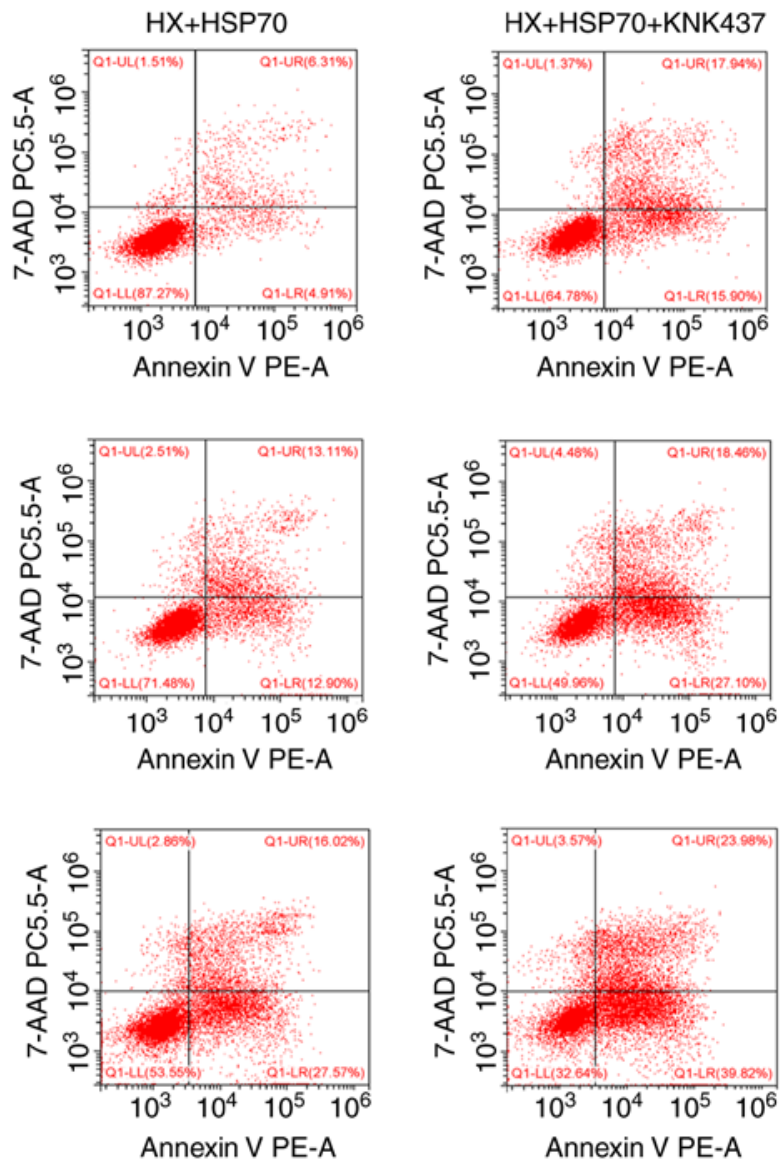

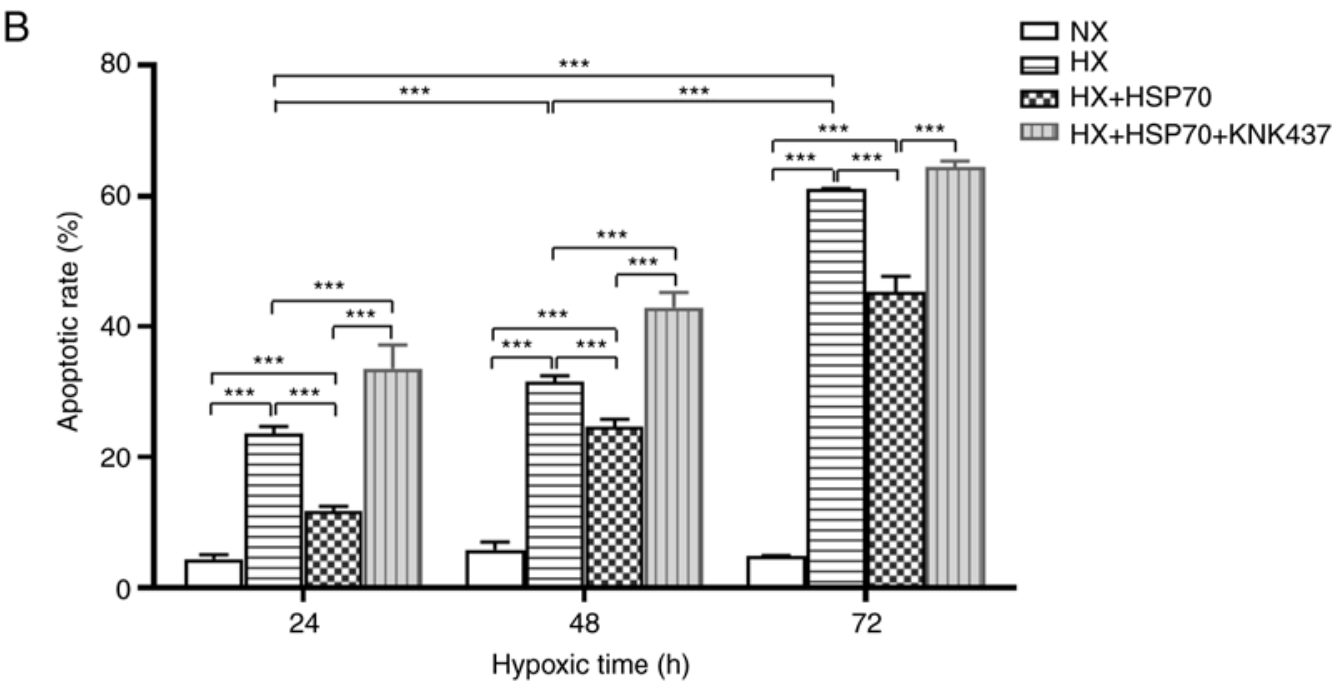

Figure 3. HSP70 inhibits hypoxia-induced apoptosis in PMVECs isolated from neonatal rats. (A) Flow cytometric analysis of the apoptotic rate of PMVECs. (B) Apoptotic rates of PMVECs were compared in the HX, NX, HX + HSP70 and HX + HSP70 + KNK437 groups. Apoptotic rates of PMVECs exposed to hypoxia for 24, 48 and $72 \mathrm{~h}$ were significantly higher compared with those of PMVECs in the NX group, and increased gradually with increasing hypoxia duration. At all tested time points during hypoxia, the PMVEC apoptotic rates in the HX + HSP70 group were significantly lower compared with those of the corresponding HX and HX + HSP70 + KNK437 groups. Data are presented as the mean \pm SD from at least three separate experiments, and were analyzed by two-way ANOVA followed by Bonferroni's post hoc test. ${ }^{* * *} \mathrm{P}<0.001$. HSP, heat shock protein; PMVECs, pulmonary microvascular endothelial cells; HX, hypoxia; NX, normoxia; KNK437, N-formyl-3,4-methylenedioxy-benzylidene-g-butyrolactam; PE, phycoerythrin; PC5.5, phycoerythrin-cyanin 5.5.

HSP70 downregulates HIF-1 $\alpha$ in hypoxia-exposed PMVECs. The mRNA and protein expression levels of HIF-1 $\alpha$ were assessed by performing RT-qPCR and western blotting, respectively, and the results were consistent with the aforementioned changes in apoptotic rates. HIF-1 $\alpha$
mRNA and protein expression levels were significantly upregulated in the HX groups compared with those in the NX groups, and HSP70 overexpression partly alleviated this increase (Fig. 6). Additionally, HIF- $1 \alpha$ mRNA and protein expression levels were significantly increased in the 

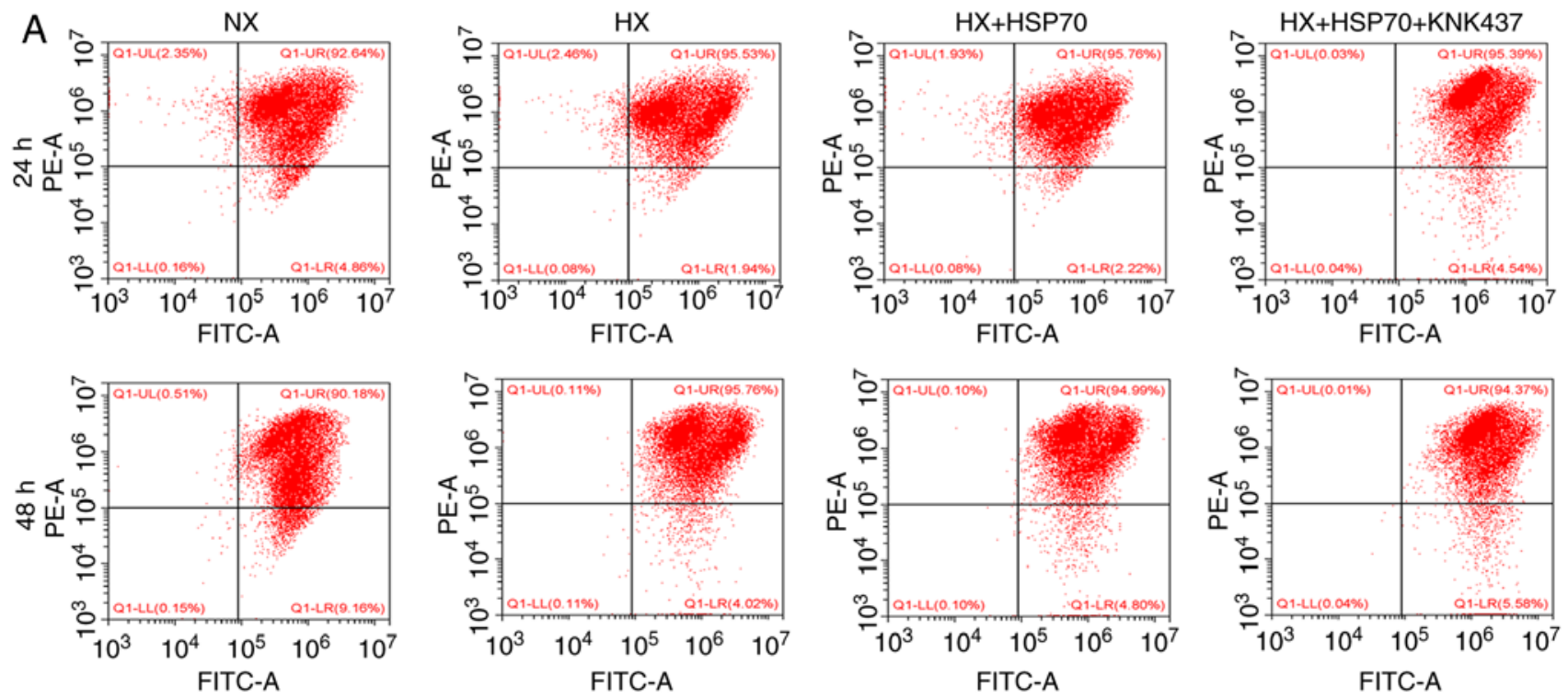

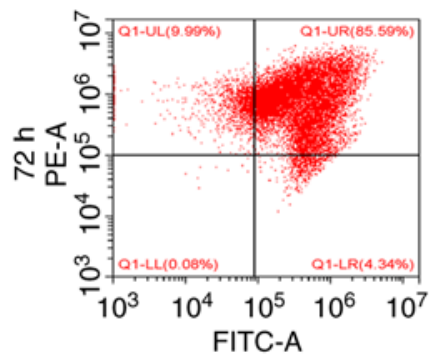

B

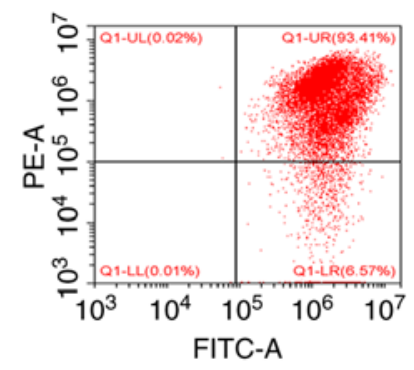

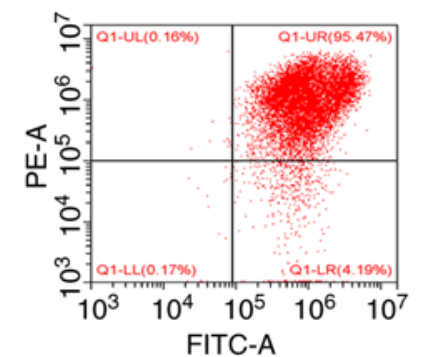

$48 \mathrm{~h}$

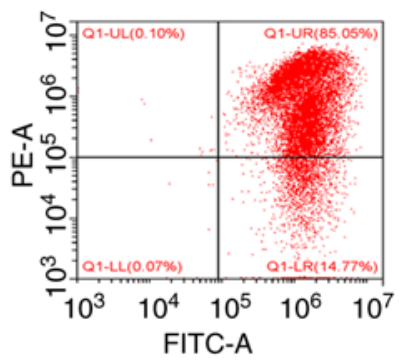

$72 \mathrm{~h}$
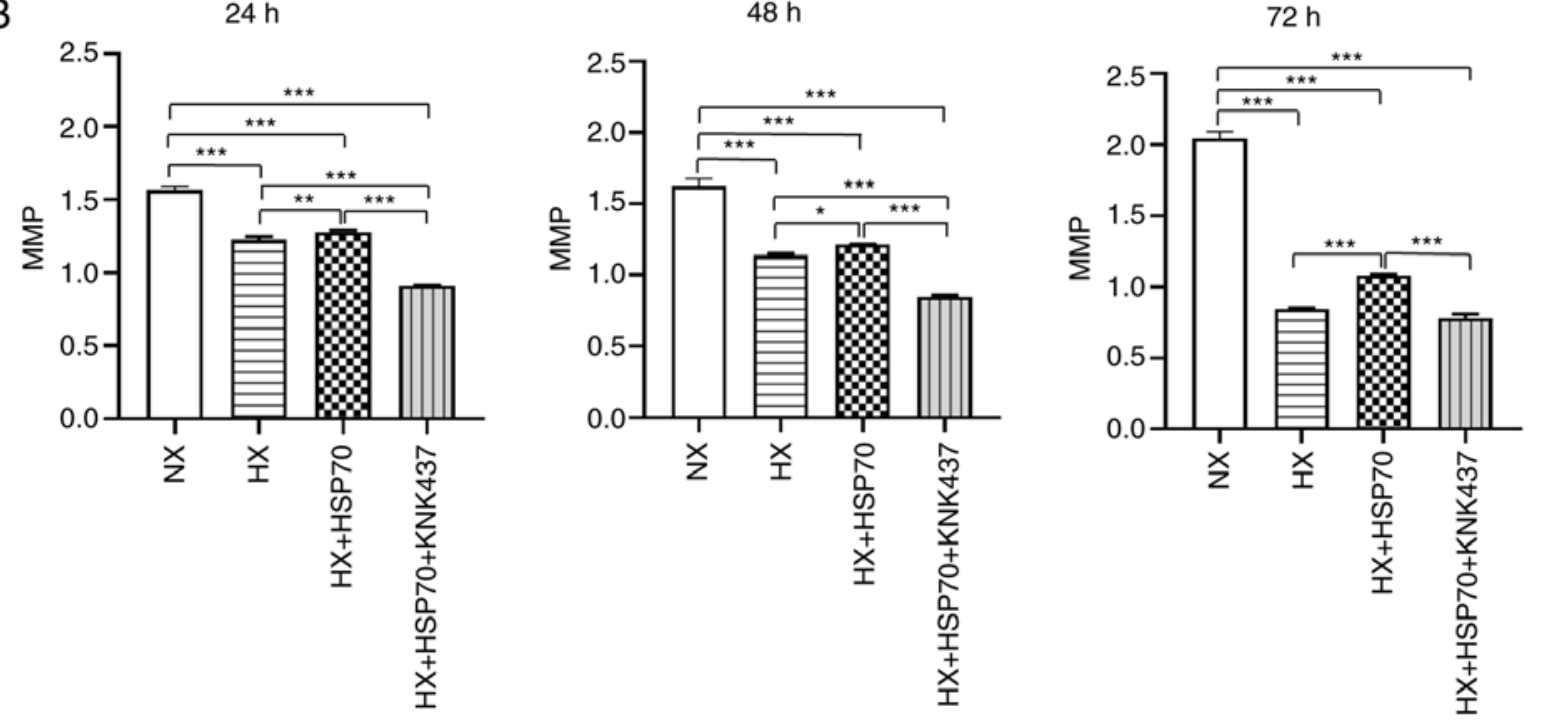

Figure 4. HSP70 inhibits hypoxia-induced MMP decrease in PMVECS isolated from neonatal rats. (A) Flow cytometric analysis of the MMP of PMVECs by JC-1. (B) MMP of PMVECs was compared in the HX, NX, HX + HSP70 and HX + HSP70 + KNK437 groups. The MMP was significantly lower in PMVECs exposed to hypoxia for 24,48 and $72 \mathrm{~h}$ compared with normoxic cells. At all tested time points during hypoxia exposure, the MMP was significantly higher in the HX + HSP70 group compared with the HX group, but lower compared with the NX group. The MMP was markedly lower in the HX + HSP70 + KNK437 group compared with that in the other two HX groups and the NX group. Data are presented as the mean \pm SD from at least three separate experiments, and were analyzed by one-way ANOVA followed by Bonferroni's post hoc test. ${ }^{*} \mathrm{P}<0.05,{ }^{* * *} \mathrm{P}<0.01$ and ${ }^{* * * *} \mathrm{P}<0.001$. HSP, heat shock protein; MMP, mitochondrial membrane potential; PMVECs, pulmonary microvascular endothelial cells; HX, hypoxia; NX, normoxia; KNK437, N-formyl-3,4-methylenedioxy-benzylidene-g-butyrolactam; PE, phycoerythrin.

$\mathrm{HX}+\mathrm{HSP} 70+\mathrm{KNK} 437$ group compared with those in the HX + HSP70 group, which was consistent with the effects of HSP70 on PMVEC apoptosis. Therefore, the protective mechanism of HSP70 against apoptosis may be associated with HIF-1 $\alpha$ expression levels.

\section{Discussion}

Endothelial cell apoptosis and dysfunction caused by uncoordinated stimulation and uncontrolled cell responses are implicated in the pathogenesis of various diseases, including 
A

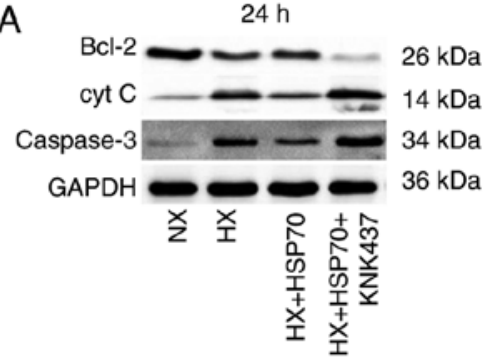

D

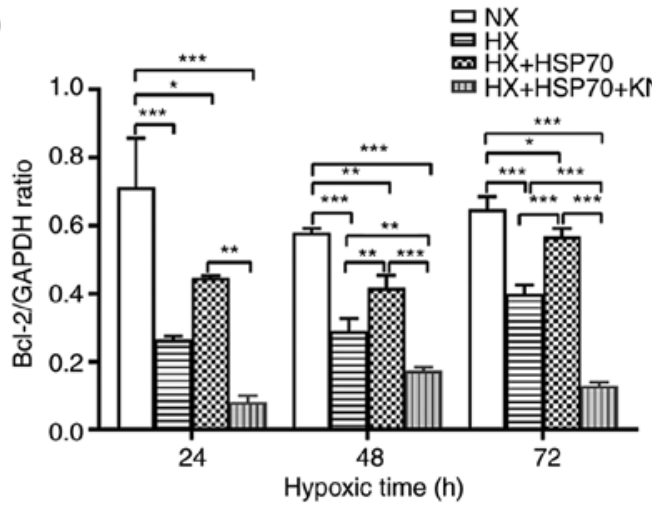

$\mathrm{F}$

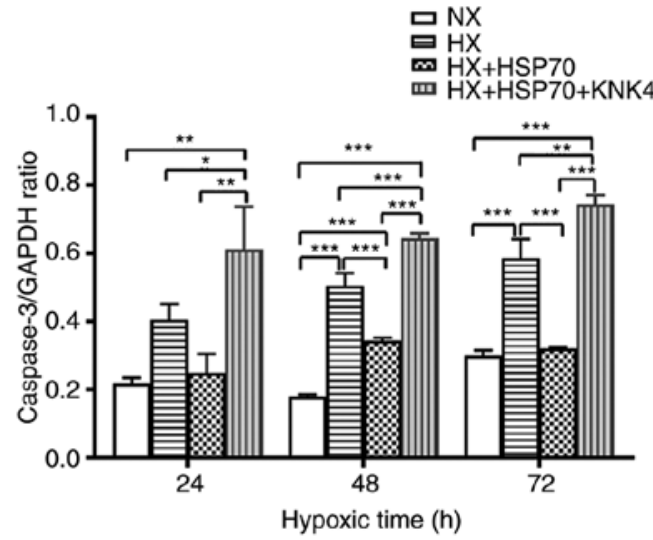

$\mathrm{H}$

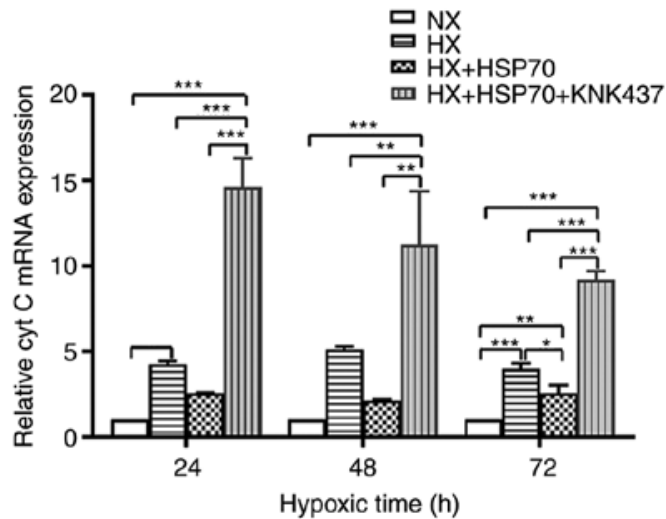

B

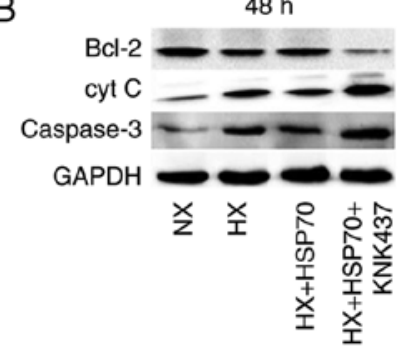

E
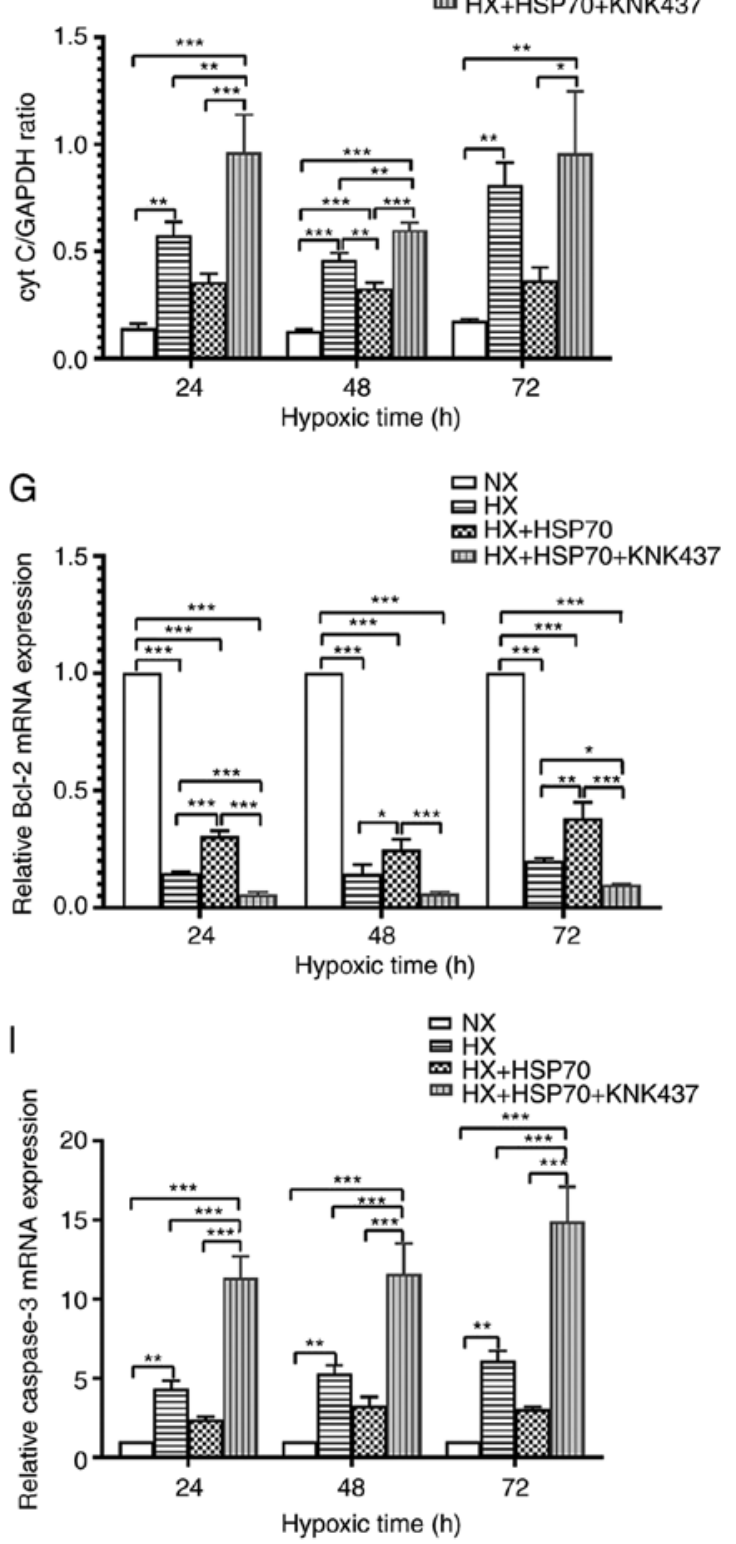

Figure 5. HSP70 regulates the protein expression levels of molecules involved in mitochondrial pathway-mediated apoptosis. At 24 , 48 and 72 h of hypoxia, (A-F) protein and (G-I) mRNA expression levels of the apoptotic inhibitor Bcl-2 and the proapoptotic factors cyt C and caspase-3 were detected. Data are presented as the mean $\pm \mathrm{SD}$ from at least three separate experiments, and were analyzed by one-way ANOVA followed by Bonferroni's post hoc test. ${ }^{*} \mathrm{P}<0.05,{ }^{* *} \mathrm{P}<0.01$ and ${ }^{* * *} \mathrm{P}<0.001$. HSP, heat shock protein; cyt C, cytochrome $c$; HX, hypoxia; NX, normoxia; KNK437, N-formyl-3,4-methylenedioxy-benzylidene-g-butyrolactam.

PH, atherosclerosis and sepsis (40). Studies on PH have reported that a higher-than-average apoptotic rate of PMVECs is the initial step in $\mathrm{PH}$ pathogenesis $(7,41)$. Neonatal $\mathrm{PH}$ is a unique form of the disease that results primarily from hypoxia, leading to difficulties in decreasing pulmonary vascular resistance, achieving continuous fetal circulation and increasing pulmonary arterial pressure (2). To explore the role of PMVEC apoptosis in the pathogenesis of $\mathrm{PH}$, the present study investigated apoptotic changes in the early stages of hypoxia in primary PMVECs derived from neonatal SD rats. 
A

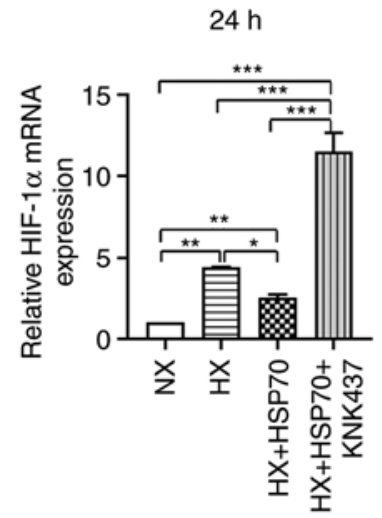

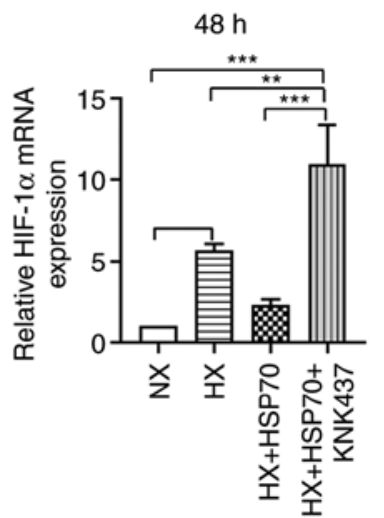

B

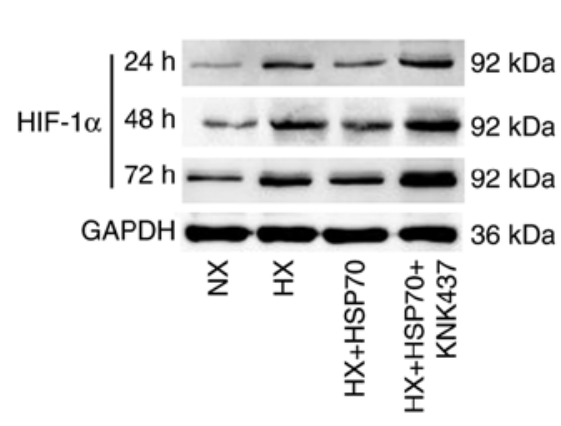

$24 \mathrm{~h}$

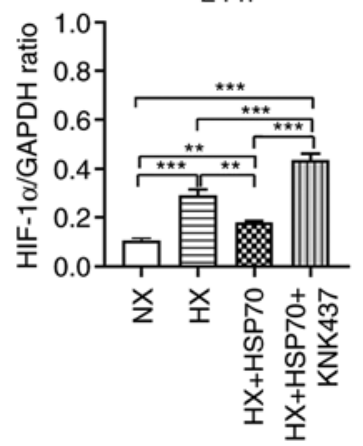

$48 \mathrm{~h}$

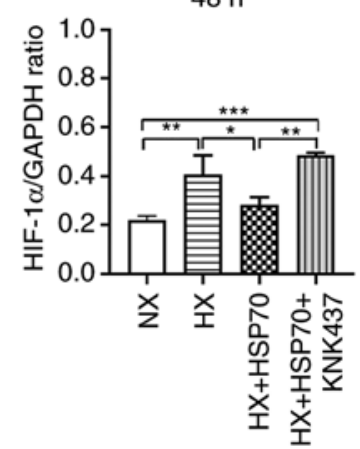

$72 \mathrm{~h}$

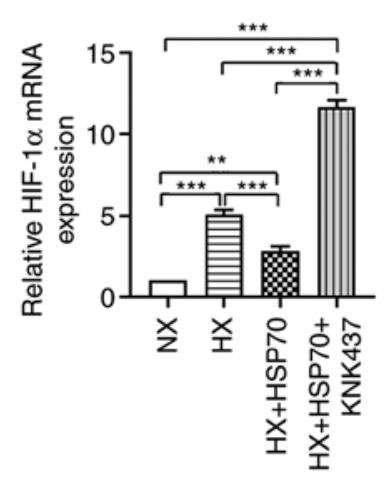

Figure 6.HIF-1 $\alpha$ mRNA and protein expression levels. (A) mRNA and (B) protein expression levels of HIF-1 $\alpha$ were examined at 24,48 and $72 \mathrm{~h}$ of hypoxia. Data are presented as the mean $\pm \mathrm{SD}$ from at least three separate experiments, and were analyzed by one-way ANOVA followed by Bonferroni's post hoc test. ${ }^{*}<0.05$, ${ }^{* *} \mathrm{P}<0.01$ and ${ }^{* * *} \mathrm{P}<0.001$. HIF-1, hypoxia-inducible factor-1; HX, hypoxia; NX, normoxia; KNK437, N-formyl-3,4-methylenedioxy-benzylidene-g-butyrolactam.

The results demonstrated that the apoptotic rate of PMVECs exposed to hypoxic conditions for $24 \mathrm{~h}$ was significantly higher compared with that in normoxic cells; the apoptotic rate gradually increased with hypoxia duration. Following $72 \mathrm{~h}$ of hypoxia exposure, the apoptotic rate was $>60 \%$. These results indicated that hypoxia-induced apoptosis of PMVECs in neonatal rats gradually increased with prolonged exposure to hypoxic conditions. The present study demonstrated that changes observed in neonatal rat PMVECs in the context of $\mathrm{PH}$ were similar to early changes in adults, where PMVECs undergo apoptosis in the early stages of hypoxia (12). This transition may be associated with the proliferation and repair of endothelial cells following apoptosis, activation of STAT-3 promoting cell survival, and dysregulation of the expression of proapoptotic and antiapoptotic factors, such as Bcl-2 and caspase family members $(42,43)$.

Our previous study revealed that HSP70 expression was increased in the lung tissues of neonatal rats with HPH, decreasing pulmonary arterial pressure and pulmonary vascular remodeling, suggesting that HSP70 may exert a protective effect against pulmonary vascular damage in this experimental system (44). However, the mechanism by which HSP70 alleviates pulmonary vascular damage remains unclear. In the present study, PMVECs isolated from neonatal rats were cultured in vitro and subjected to hypoxia, whereby PMVEC apoptosis increased with prolonged hypoxia exposure. Furthermore, HSP70 expression levels were significantly upregulated in hypoxic PMVECs compared with those in normoxic conditions, indicating that HSP70 may be involved in the apoptotic response of PMVECs to hypoxia. Lentivirus-mediated overexpression of HSP70 in PMVECs significantly decreased the apoptotic rate of the cells in the early stages of hypoxia. On the other hand, KNK437-treated PMVECs displayed significantly attenuated overexpression of exogenous HSP70 and significant inhibition of the aforementioned effects of HSP70 on hypoxia-induced PMVEC apoptosis. Although KNK437 did not decrease the expression levels of HSP70 in HSP70-overexpression PMVECs under hypoxic conditions compared with cells exposed to hypoxia alone, it significantly increased the PMVEC apoptotic rate. This outcome may be a result of the exacerbation of abnormal synthesis and release of apoptotic inhibitors and proapoptotic factors following KNK437-mediated downregulation of HSP70. The changes detected in apoptosis-related factors also supported this hypothesis. Moreover, these results suggested that HSP70 may serve a protective role in the structure and function of PMVECs in neonatal rats by inhibiting PMVEC apoptosis under hypoxia. This role is similar to that of HSP70 in inhibiting apoptosis of tumor cells (17), ischemic cardiomyocytes (21) and infected pulmonary vascular endothelial cells (22). Considering these findings and the results of our previous in vivo study (44), it could be speculated that HSP70 may reduce pulmonary vascular damage and delay the progression of neonatal HPH by inhibiting PMVEC apoptosis in the early stages of the disease.

The mitochondrial apoptotic pathway is important for normal cell function; when cells encounter foreign stimuli, the levels of the antiapoptotic protein Bcl-2 are downregulated, 
whereas the proapoptotic proteins Bax and BAD are activated and upregulated. Furthermore, the $\mathrm{Bax} / \mathrm{Bcl}-2$ ratio is increased, leading to a decrease in the MMP, an increase in mitochondrial permeability and the release of large amounts of cyt $C$ from the mitochondria $(14,45)$. These changes activate the caspase family of proteins and induce mitochondrial pathway-mediated apoptosis. Researchers have reported that overexpression of HSP70 affects mitochondrial apoptotic pathway-mediated inhibition of ovarian cancer cell apoptosis by increasing the MMP and interfering with the release of cyt $\mathrm{C}$ and AIF, caspase activation and misfolded protein accumulation $(19,46)$. In addition, Kondrikov et al (14) demonstrated that HSP70 alleviates hyperoxia-induced damage to the pulmonary endothelial barrier by inhibiting PMVEC apoptosis via the mitochondrial caspase and AIF pathway. In the present study, the associations between HSP70, MMP, Bcl-2, cyt $\mathrm{C}$ and caspase- 3 were analyzed to determine the effects of HSP70 on mitochondrial pathway-mediated apoptosis of PMVECs. The results indicated that hypoxia decreased the MMP (more noticeably after $72 \mathrm{~h}$ of hypoxia) and Bcl-2 mRNA and protein expression levels, but increased the mRNA and protein expression levels of the proapoptotic proteins cyt $\mathrm{C}$ and caspase- 3 compared with those in the normoxia group, inferring that hypoxia induced PMVEC apoptosis via the mitochondrial pathway. Under hypoxic conditions, overexpression of HSP70 in PMVECs resulted in increases in the MMP and Bcl-2 expression levels, and decreased expression of cyt $\mathrm{C}$ and caspase- 3 after 24,48 and 72 h of hypoxia, whereas HSP70 inhibition exerted the opposite effects, suggesting that HSP70 may inhibit PMVEC apoptosis via the mitochondrial pathway.

HIF-1 $\alpha$, a major factor in the regulation of cellular oxygen homeostasis, is involved in the pathogenesis of cancer, $\mathrm{PH}$, ischemic disease and infections (26,47-49). Our previous study has demonstrated that exogenous HSP70 reduces pulmonary artery pressure, weakens pulmonary vascular remodeling and blocks pulmonary vascular damage by inhibiting the expression of HIF-1 $\alpha$ in the lung tissues of neonatal rats with HPH (42). The present study further investigated the involvement of HIF- $1 \alpha$ in the process of HSP70-mediated inhibition of apoptosis in neonatal rat PMVEC cultures exposed to hypoxia. The results demonstrated that HIF- $1 \alpha$ mRNA and protein expression levels were significantly increased in PMVECs exposed to hypoxia compared with those in cells maintained under normoxic conditions. HIF-1 $\alpha$ upregulation was accompanied by an increased PMVEC apoptotic rate. In addition, in hypoxic conditions, HIF-1 $\alpha$ expression levels and apoptotic rate were reduced in HSP70-overexpressing PMVECs; however, these factors were significantly increased in PMVECs treated with an HSP70 inhibitor. Therefore, it was hypothesized that HSP70 inhibited apoptosis in PMVECs under hypoxia, which may be associated with HSP70-mediated downregulation of HIF-1 $\alpha$. The association between HIF-1 $\alpha$ and apoptosis varies between different cell types; in cervical and thyroid studies, HIF-1 $\alpha$ has been reported to participate in the mechanisms of tumor cells protection and chemotherapeutic resistance through antiapoptotic properties and thus, HIF-1 $\alpha$ may serve as an effective therapeutic target for tumors $(50,51)$. In a recent study assessing myocardial damage caused by hyperglycemia, HIF-1 $\alpha$ expression in the rat myoblast cell line $\mathrm{H} 9 \mathrm{c} 2$ was demonstrated to significantly increase following apoptotic induction by high glucose (52). In the same study, silencing HIF-1 $\alpha$ with small interfering RNAs or reducing HIF-1 $\alpha$ expression levels using propofol significantly attenuated apoptosis, indicating that HIF-1 $\alpha$ may promote apoptosis in $\mathrm{H} 9 \mathrm{c} 2$ cells exposed to high concentrations of glucose (52). The results of the present study suggested that HIF-1 $\alpha$ may promote apoptosis in neonatal rat PMVECs exposed to hypoxia, however, the exact underlying molecular mechanism requires further investigation.

The present study had several limitations that warrant further explanation and should be investigated in future studies. Firstly, the impact of HSP70 on PMVEC function was inferred but not confirmed, thus further research is required. Secondly, the effects of HSP70 on the apoptosis of neonatal rat PMVECs under hypoxia require further validation in vivo. Lastly, the association between HIF-1 $\alpha$ and PMVEC apoptosis should be further elucidated.

In summary, the results of the present study demonstrated that exposure of neonatal rat PMVECs to hypoxia in vitro gradually elevated the apoptotic rate with increasing exposure time. HSP70 and HIF-1 $\alpha$ expression levels were also upregulated under hypoxic conditions compared with cells maintained under normoxic conditions. Overexpression of HSP70 attenuated PMVEC apoptosis via the mitochondrial pathway under hypoxia, whereas its inhibition increased the apoptotic rate. The mechanism by which HSP70 regulates hypoxia-induced apoptosis in PMVECs isolated from neonatal rats may involve HSP70-mediated downregulation of HIF-1 $\alpha$. Based on these results, we hypothesize that $\mathrm{HSP} 70$ reduces pulmonary vascular damage in neonatal HPH by inhibiting PMVEC apoptosis, providing a novel target for the treatment of this disease.

\section{Acknowledgements}

Not applicable.

\section{Funding}

The present study was supported by the National Natural Science Foundation of China (grant no. 81760278).

\section{Availability of data and materials}

The datasets used and/or analyzed during the current study are available from the corresponding author on reasonable request.

\section{Authors' contributions}

YM and ML designed and supervised the study, and revised the manuscript. JC and LY performed the experiments and drafted the manuscript. LW supervised the experiments, analyzed the data and revised the manuscript critically for important intellectual content. DW and QZ performed the experiments and analyzed the data. JC and LW confirm the authenticity of all the raw data. All authors read and approved the final manuscript.

\section{Ethics approval and consent to participate}

The present study followed internationally recognized guidelines on animal welfare, as well as local and national 
regulations, in accordance with the UK Animals (Scientific Procedures) Act and associated guidelines (53), the EU Directive 2010/63/EU for animal experiments (54) and the National Institutes of Health guide for the care and use of laboratory animals (55). The study complied with the Animal Research: Reporting of in vivo Experiments guidelines (56) and the American Veterinary Medical Association euthanasia guidelines 2013 (57). All animal experiments were approved by the Animal Ethics Committee of the First Affiliated Hospital of Xinjiang Medical University (Ürümqi, China; approval no. IACUC-20170214029).

\section{Patient consent for publication}

Not applicable.

\section{Competing interests}

The authors declare that they have no competing interests.

\section{References}

1. Walsh-Sukys MC, Tyson JE, Wright LL, Bauer CR, Korones SB, Stevenson DK, Verter J, Stoll BJ, Lemons JA, Papile LA, et al: Persistent pulmonary hypertension of the newborn in the era before nitric oxide: Practice variation and outcomes. Pediatrics 105 (1 Pt 1): 14-20, 2000.

2. Distefano G and Sciacca P: Molecular physiopathogenetic mechanisms and development of new potential therapeutic strategies in persistent pulmonary hypertension of the newborn. Ital J Pediatr 41: 6, 2015.

3. Du Y, Fu J, Yao L, Qiao L, Liu N, Xing Y and Xue X: Altered expression of PPAR-Y and TRPC in neonatal rats with persistent pulmonary hypertension. Mol Med Rep 16: 1117-1124, 2017.

4. Dabral S, Tian X, Kojonazarov B, Savai R, Ghofrani HA, Weissmann N, Florio M, Sun J, Jonigk D, Maegel L, et al: Notch1 signalling regulates endothelial proliferation and apoptosis in pulmonary arterial hypertension. Eur Respir J 48: 1137-1149, 2016.

5. Hudalla H, Michael Z, Christodoulou N, Willis GR, Fernandez-Gonzalez A, Filatava EJ, Dieffenbach P, Fredenburgh LE, Stearman RS, Geraci MW, et al: Carbonic anhydrase inhibition ameliorates inflammation and experimental pulmonary hypertension. Am J Respir Cell Mol Biol 61: 512-524, 2019.

6. Majka S, Hagen M, Blackwell T, Harral J, Johnson JA, Gendron R, Paradis H, Crona D, Loyd JE, Nozik-Grayck E, et al: Physiologic and molecular consequences of endothelial Bmpr2 mutation. Respir Res 12: 84, 2011.

7. Sakao S, Taraseviciene-Stewart L, Lee JD, Wood K, Cool CD and Voelkel NF: Initial apoptosis is followed by increased proliferation of apoptosis-resistant endothelial cells. FASEB J 19 $1178-1180,2005$.

8. Rhodes CJ, Im H, Cao A, Hennigs JK, Wang L, Sa S, Chen PI, Nickel NP, Miyagawa K, Hopper RK, et al: RNA sequencing analysis detection of a novel pathway of endothelial dysfunction in pulmonary arterial hypertension. Am J Respir Crit Care Med 192: 356-366, 2015.

9. Singh N, Singh H, Jagavelu K, Wahajuddin M and Hanif K: Fatty acid synthase modulates proliferation, metabolic functions and angiogenesis in hypoxic pulmonary artery endothelial cells. Eur J Pharmacol 815: 462-469, 2017.

10. Guerard P, Rakotoniaina Z, Goirand F, Rochette L, Dumas M, Lirussi $\mathrm{F}$ and Bardou M: The HMG-CoA reductase inhibitor, pravastatin, prevents the development of monocrotaline-induced pulmonary hypertension in the rat through reduction of endothelial cell apoptosis and overexpression of eNOS. Naunyn Schmiedebergs Arch Pharmacol 373: 401-414, 2006.

11. Yeager ME, Halley GR, Golpon HA, Voelkel NF and Tuder RM: Microsatellite instability of endothelial cell growth and apoptosis genes within plexiform lesions in primary pulmonary hypertension. Circ Res 88: E2-E11, 2001.
12. Masri FA, Xu W, Comhair SA, Asosingh K, Koo M, Vasanji A, Drazba J, Anand-Apte B and Erzurum SC: Hyperproliferative apoptosis-resistant endothelial cells in idiopathic pulmonary arterial hypertension. Am J Physiol Lung Cell Mol Physiol 293: L548-L554, 2007.

13. Schultz A, Olorundami OA, Teng RJ, Jarzembowski J, Shi ZZ, Kumar SN, Pritchard K Jr, Konduri GG and Afolayan AJ: Decreased OLA1 (Obg-Like ATPase-1) expression drives ubiquitin-proteasome pathways to downregulate mitochondrial SOD2 (Superoxide Dismutase) in persistent pulmonary hypertension of the newborn. Hypertension 74: 957-966, 2019.

14. Kondrikov D, Fulton D, Dong Z and Su Y: Heat shock protein 70 prevents hyperoxia-induced disruption of lung endothelial barrier via caspase-dependent and AIF-dependent pathways. PLos One 10: e0129343, 2015.

15. Li X, Kanegasaki S, Jin F, Deng Y, Kim JR, Chang HW and Tsuchiya T: Simultaneous induction of HSP70 expression, and degranulation, in IgE/Ag-stimulated or extracellular HSP70-stimulated mast cells. Allergy 73: 361-368, 2018.

16. Aghdassi A, Phillips P, Dudeja V, Dhaulakhandi D, Sharif R, Dawra R, Lerch MM and Saluja A: Heat shock protein 70 increases tumorigenicity and inhibits apoptosis in pancreatic adenocarcinoma. Cancer Res 67: 616-625, 2007.

17. Kumar S, Stokes J 3rd, Singh UP, Scissum Gunn K, Acharya A, Manne U and Mishra M: Targeting Hsp70: A possible therapy for cancer. Cancer Lett 374: 156-166, 2016.

18. van Noort JM, Bugiani M and Amor S: Heat shock proteins: Old and novel roles in neurodegenerative diseases in the central nervous system. CNS Neurol Disord Drug Targets 16: 244-256, 2017.

19. Garrido C, Brunet M, Didelot C, Zermati Y, Schmitt E and Kroemer G: Heat shock proteins 27 and 70: Anti-apoptotic proteins with tumorigenic properties. Cell Cycle 5: 2592-2601, 2006.

20. Ciocca DR and Calderwood SK: Heat shock proteins in cancer: Diagnostic, prognostic, predictive, and treatment implications. Cell Stress Chaperones 10: 86-103, 2005.

21. Ranek MJ, Stachowski MJ, Kirk JA and Willis MS: The role of heat shock proteins and co-chaperones in heart failure. Philos Trans R Soc Lond B Biol Sci 373: 20160530, 2018.

22. Li X, Yu Y, Gorshkov B, Haigh S, Bordan Z, Weintraub D, Rudic RD, Chakraborty T, Barman SA, Verin AD, et al: Hsp70 suppresses mitochondrial reactive oxygen species and preserves pulmonary microvascular barrier integrity following exposure to bacterial toxins. Front Immunol 9: 1309, 2018.

23. Semenza GL: The genomics and genetics of oxygen homeostasis. Annu Rev Genomics Hum Genet 21: 183-204, 2020.

24. Wang L, Zhou Y, Li M and Zhu Y: Expression of hypoxia-inducible factor- $1 \alpha$, endothelin-1 and adrenomedullin in newborn rats with hypoxia-induced pulmonary hypertension. Exp Ther Med 8: 335-339, 2014

25. Veith C, Schermuly RT, Brandes RP and Weissmann N: Molecular mechanisms of hypoxia-inducible factor-induced pulmonary arterial smooth muscle cell alterations in pulmonary hypertension. J Physiol 594: 1167-1177, 2016.

26. Chen S and Sang N: Hypoxia-inducible factor-1: A critical player in the survival strategy of stressed cells. J Cell Biochem 117: 267-278, 2016

27. Zhao L, Ma R, Zhang L, Yuan X, Wu J, He L, Liu G and Du R: Inhibition of HIF-1a-mediated TLR4 activation decreases apoptosis and promotes angiogenesis of placental microvascular endothelial cells during severe pre-eclampsia pathogenesis. Placenta 83: 8-16, 2019.

28. Xie RY, Fang XL, Zheng XB, Lv WZ, Li YJ, Ibrahim Rage H, He QL, Zhu WP and Cui TX: Salidroside and FG-4592 ameliorate high glucose-induced glomerular endothelial cells injury via HIF upregulation. Biomed Pharmacother 118: $109175,2019$.

29. Leong KH, Zhou LL, Lin QM, Wang P, Yao L and Huang ZJ: Therapeutic effects of various methods of MSC transplantation on cerebral resuscitation following cardiac arrest in rats. Mol Med Rep 13: 3043-3051, 2016.

30. Liu M, Liu Q, Pei Y, Gong M, Cui X, Pan J, Zhang Y, Liu Y, Liu Y, Yuan X, et al: Aqp-1 gene knockout attenuates hypoxic pulmonary hypertension of mice. Arterioscler Thromb Vasc Biol 39: 48-62, 2019.

31. Yang YD, Li MM, Xu G, Zhang EL, Chen J, Sun B, Chen DW and Gao YQ: Targeting mitochondria-associated membranes as a potential therapy against endothelial injury induced by hypoxia. J Cell Biochem 120: 18967-18978, 2019. 
32. Koishi M, Yokota S, Mae T, Nishimura Y, Kanamori S, Horii N, Shibuya K, Sasai K and Hiraoka M: The effects of KNK437, a novel inhibitor of heat shock protein synthesis, on the acquisition of thermotolerance in a murine transplantable tumor in vivo. Clin Cancer Res 7: 215-219, 2001.

33. Shiota M, Kusakabe H, Izumi Y, Hikita Y, Nakao T, Funae Y, Miura $\mathrm{K}$ and Iwao H: Heat shock cognate protein 70 is essential for Akt signaling in endothelial function. Arterioscler Thromb Vasc Biol 30: 491-497, 2010.

34. Bozaykut P, Sozen E, Kaga E, Ece A, Ozaltin E, Bergquist J, Kartal Ozer N and Karademir Yilmaz B: HSP70 inhibition leads to the activation of proteasomal system under mild hyperthermia conditions in young and senescent fibroblasts. Oxid Med Cell Longev 2020: 9369524, 2020.

35. Chung JW, Piao ZH, Yoon SR, Kim MS, Jeong M, Lee SH, Min JK, Kim JW, Cho YH, Kim JC, et al: Pseudomonas aeruginosa eliminates natural killer cells via phagocytosis-induced apoptosis. PLoS Pathog 5: e1000561, 2009.

36. Zhang H, Liu Y, Wang L, Li Z, Zhang H, Wu J, Rahman N, Guo Y, Li D, Li N, et al: Differential effects of estrogen/androgen on the prevention of nonalcoholic fatty liver disease in the male rat. J Lipid Res 54: 345-357, 2013.

37. Livak KJ and Schmittgen TD: Analysis of relative gene expression data using real-time quantitative PCR and the 2(-Delta Delta C(T)) method. Methods 25: 402-408, 2001.

38. Wu YL, Li ZL, Zhang XB and Liu H: Yinchenhao decoction attenuates obstructive jaundice-induced liver injury and hepatocyte apoptosis by suppressing protein kinase RNA-like endoplasmic reticulum kinase-induced pathway. World J Gastroenterol 25: 6205-6221, 2019.

39. Du ZD, Wei W, Yu S, Song QL, Liu K and Gong SS: NADPH oxidase 2-mediated insult in the auditory cortex of zucker diabetic fatty rats. Neural Plast 2019: 3591605, 2019.

40. Sakao S, Tatsumi K and Voelkel NF: Endothelial cells and pulmonary arterial hypertension: Apoptosis, proliferation, interaction and transdifferentiation. Respir Res 10: 95, 2009.

41. Teichert-Kuliszewska K, Kutryk MJ, Kuliszewski MA Karoubi G, Courtman DW, Zucco L, Granton J and Stewart DJ: Bone morphogenetic protein receptor- 2 signaling promotes pulmonary arterial endothelial cell survival: Implications for loss-of-function mutations in the pathogenesis of pulmonary hypertension. Circ Res 98: 209-217, 2006.

42. Pullamsetti SS, Savai R, Seeger W and Goncharova EA: Translational advances in the field of pulmonary hypertension. From cancer biology to new pulmonary arterial hypertension therapeutics. Targeting cell growth and proliferation signaling hubs. Am J Respir Crit Care Med 195: 425-437, 2017.

43. Marshall JD, Bazan I,Zhang Y,Fares WH and LeePJ: Mitochondria dysfunction and pulmonary hypertension: Cause, effect, or both. Am J Physiol Lung Cell Mol Physiol 314: L782-L796, 2018.

44. Wang L and Li MX: Roles of heat shock protein 70 toward hypoxia-inducible factor $1 \alpha(\mathrm{HIF}-1 \alpha)$ blockade in newborn rats with hypoxia-induced pulmonary hypertension. Int J Clin Exp Med 11: 13520-13527, 2018.
45. Pena-Blanco A and Garcia-Saez AJ: Bax, Bak and beyond-mitochondrial performance in apoptosis. FEBS J 285: 416-431, 2018

46. Hoter A and Naim HY: Heat shock proteins and ovarian cancer: Important roles and therapeutic opportunities. Cancers (Basel) 11: 1389, 2019.

47. Dabral S, Muecke C, Valasarajan C, Schmoranzer M, Wietelmann A, Semenza GL, Meister M, Muley T, Seeger-Nukpezah T, Samakovlis C, et al: A RASSF1A-HIF1a loop drives Warburg effect in cancer and pulmonary hypertension. Nat Commun 10: 2130, 2019.

48. Devraj G, Beerlage C, Brune B and Kempf VA: Hypoxia and HIF-1 activation in bacterial infections. Microbes Infect 19: 144-156, 2017.

49. Ham PB 3rd and Raju R: Mitochondrial function in hypoxic ischemic injury and influence of aging. Prog Neurobiol 157: 92-116, 2017.

50. Mylonis I, Kourti M, Samiotaki M, Panayotou G and Simos G: Mortalin-mediated and ERK-controlled targeting of HIF-1 $\alpha$ to mitochondria confers resistance to apoptosis under hypoxia. J Cell Sci 130: 466-479, 2017.

51. Zhou L, Cha G, Chen L, Yang C, Xu D and Ge M: HIF1 $\alpha /$ PD-L1 axis mediates hypoxia-induced cell apoptosis and tumor progression in follicular thyroid carcinoma. Onco Targets Ther 12 6461-6470, 2019.

52. Pu J, Zhu S, Zhou D, Zhao L, Yin M, Wang Z and Hong J: Propofol alleviates apoptosis induced by chronic high glucose exposure via regulation of HIF-1 $\alpha$ in H9c2 cells. Oxid Med Cell Longev 2019: 4824035, 2019.

53. Hollands C: The animals (Scientific Procedures) ACT 1986 Lancet 2: 32-33, 1986

54. European Parliament: Directive 2010/63/EU of the European Parliament and of the Council of 22 September 2010 on the protection of animals used for scientific purposes. Official J Eur Union 276: 33-79, 2010.

55. National Research Council (US) Committee for the Update of the Guide for the Care and Use of Laboratory Animals: Guide for the Care and Use of Laboratory Animals. 8th edition. National Academies Press, Washington, DC, 2011.

56. McGrath JC, Drummond GB, McLachlan EM, Kilkenny C and Wainwright CL: Guidelines for reporting experiments involving animals: The ARRIVE guidelines. Br J Pharmacol 160: $1573-1576,2010$

57. American Veterinary Medical Association (AVMA): AVMA Guidelines for the Euthanasia of Animals: 2013 Edition. AVMA, Schaumburg, IL, pp67-73, 2013.

This work is licensed under a Creative Commons Attribution-NonCommercial-NoDerivatives 4.0 International (CC BY-NC-ND 4.0) License. 